\title{
PHARYNGEAL MOTOR CONTROL AND THE PATHOGENESIS OF OBSTRUCTIVE SLEEP APNEA
}

\author{
Amy S Jordan ${ }^{1,2}$ and David $\mathbf{P}$ White ${ }^{1,2}$ \\ ${ }^{1}$ Brigham and Women's Hospital, Boston, MA 02115 \\ ${ }^{2}$ Harvard Medical School, Boston, MA 02115
}

\begin{abstract}
The upper airway in patients with obstructive sleep apnea (OSA) is thought to collapse during sleep at least in part, because of a sleep related reduction in upper airway dilator muscle activity. Therefore a comprehensive understanding of the neural regulation of these muscles is warranted. The dilator muscles can be classified in two broad categories; those that have respiratory related activity and those that fire constantly throughout the respiratory cycle. The motor control of these two groups likely differs with the former receiving input from respiratory neurons and negative pressure reflex circuits. The activity of both muscle groups is reduced shortly after sleep onset, indicating that both receive input from brainstem neurons involved in sleep regulation. In the apnea patient, this may lead to pharyngeal airway collapse. This review briefly describes the currently proposed sleep and respiratory neural pathways and how these circuits interact with the upper airway dilator muscle motorneurones, including recent evidence from animal studies.
\end{abstract}

\section{GENERAL INTRODUCTION}

Obstructive Sleep Apnea (OSA) is a disorder of repetitive upper airway collapse during sleep that affects at least 2-4\% of the adult US population (Young et al., 1993). During airway collapse, ventilation is reduced (hypopnea) or absent (apnea) and hypoxia and hypercapnia develop. These blood gas changes increase respiratory drive until the upper airway re-opens (which is often associated with an arousal from sleep), at which time ventilation increases to reverse the blood gas abnormalities. Both the blood gas disturbance and arousal from sleep stimulate the sympathetic nervous system resulting in surges of blood pressure. Thus, OSA results in cycles of hypoxia/hypercapnia, sympathetic activation, and substantial sleep fragmentation. These events likely contribute to the consequences of OSA which include excessive daytime sleepiness (Punjabi et al., 1999), neurocognitive impairment (Kim et al., 1997) and increased risk for car and workplace accidents (Young et al., 1997). OSA also appears to be causally related to hypertension (Brooks et al., 1997; Peppard et al., 2000; Pepperell et al., 2002) and may increase the risk of stroke, sudden death from any cause (Arzt et al., 2005; Yaggi et al., 2005), and myocardial infarction (Doherty et al., 2005; Marin et al., 2005).

Corresponding author: Amy S Jordan, PhD, Sleep Disorders Program @ BIDMC, 75 Francis St, Boston, MA, 02115, Ph - (617) 278 0911, Fax - (617) 732 7337, E-mail: ajordan@ rics.bwh.harvard.edu.

Publisher's Disclaimer: This is a PDF file of an unedited manuscript that has been accepted for publication. As a service to our customers we are providing this early version of the manuscript. The manuscript will undergo copyediting, typesetting, and review of the resulting proof before it is published in its final citable form. Please note that during the production process errors may be discovered which could affect the content, and all legal disclaimers that apply to the journal pertain. 
Pharyngeal collapse in OSA is thought to occur in part because patients have an anatomically small upper airway (Schwab et al., 1995; Schwab, 2003; Strohl, 2003). However, most patients with OSA can breathe normally and maintain normal blood gas tensions during wakefulness. This appears to be related to the high level of upper airway dilator muscle activity present during wakefulness in OSA patients (Mezzanotte et al., 1992) thereby compensating for the deficient anatomy. At sleep onset upper airway dilator muscle activity is reduced in both OSA patients and controls (Fogel et al., 2005) and this likely contributes to airway collapse in the patients with OSA and the increase in airway resistance observed in healthy individuals (Kay et al., 1994; Trinder et al., 1997). However, if this were the sole explanation for OSA then patients would be expected to have apnea at all times during sleep and in all sleep stages. OSA has long been recognized to be more severe in rapid eye movement (REM) sleep than nonREM (NREM) sleep and in stage 2 compared to slow wave sleep (SWS). In addition, Younes recently reported that most patients with OSA have some periods of sleep without repetitive apneas or hypopneas (Younes, 2003) indicating that many patients can overcome their anatomic abnormality some of the time during sleep. Data from our own laboratory indicate that when patients with OSA spontaneously overcome their anatomic abnormality and achieve stable breathing, the activity of at least one upper airway dilator muscle (the genioglossus) is highly active (Jordan et al., 2005). This suggests that activation of upper airway muscles is possible during sleep and may prevent upper airway collapse at least part of the time in some patients. This review will provide an update on what is known about pharyngeal motor control since prior reviews on this topic (Horner, 2001; Series, 2002). First the dilator muscles will be reviewed and the control of the muscles during wake and sleep described. This will be followed by a description of the neural regulation of sleep and breathing and potential neural pathways responsible for the sleep related changes in dilator muscle activity will be proposed. As airway dilator muscle activity during REM sleep is quite different from NREM sleep and has received less attention it will not be covered in this review. However, it has been discussed in prior reviews (Horner, 2001).

\section{OVERVIEW OF PHARYNGEAL ANATOMY AND MUSCULATURE}

The pharyngeal airway extends from the epiglottis to the nasal choanae (Figure 1) and is, with the exception of the posterior pharyngeal wall, largely unsupported by bony structures making it susceptible to collapse with the negative pressures generated during inspiration. The airway has therefore often been considered a collapsible tube, which behaves like a Starling resistor. In this model, the airflow through the tube is determined by the collapsibility of the tube wall (pharyngeal airway wall distensibility), the pressure driving flow through the tube (epiglottis and choanal pressures or just choanal pressure in a flow limited pharyngeal airway) and the pressure outside of the collapsible tube (extraluminal airway pressure in the case of the pharyngeal airway). As airway collapse in OSA occurs primarily in the pharyngeal airway and pharyngeal dilator muscles can influence both airway wall deformability and tissue pressure, the control of these muscles will be the focus of this review. However, we fully recognize that a number of other variables including pharyngeal anatomy, ventilatory control stability, respiratory arousal threshold, and sleep effects on lung volume among others can play an important role in apnea pathogenesis (Jordan et al., 2003).

There are a number of muscles that surround the pharyngeal airway and influence its patency. These muscles can actively dilate and open the airway, or may just stiffen the soft tissue structures such that they are less prone to deformation by negative pharyngeal pressure. These muscles have been reviewed in detail elsewhere (Horner, 1996; White, 1999; Kubin and Davies, 2002) and thus will only be briefly described here. The muscles of greatest relevance to the pharyngeal airway include the genioglossus muscle (an extrinsic tongue muscle), the palatal muscles (tensor veli palatini, levator veli palatini, musculus uvulae, palatoglossus and 
palatopharyngeus), the pharyngeal constrictor muscles and the muscles influencing hyoid position (mylohyoid, geniohyoid, stylohyoid, thyrohyoid and sternohyoid).

\subsection{The genioglossus muscle}

The genioglossus (GG) is an extrinsic tongue muscle and is the largest upper airway dilator muscle. Contraction of the GG results in anterior movement of the tongue and widening of the oropharyngeal airway in the anterior-posterior dimension (Kobayashi et al., 1996). The genioglossus is innervated by the medial branch of the hypoglossal nerve and receives input from the respiratory central pattern generator, negative pressure receptors within the upper airway and the neurons that regulate state (sleep, discussed in detail below). As a result, GG activity is increased during inspiration (phasic respiratory activity), which is thought to prevent collapse due to negative airway pressure generated during inspiration. The genioglossus is involved in many other functions and therefore also receives inputs from other brain regions (such as the swallowing central pattern generator). However, the inputs relating to these functions will not be considered here. Much of this review will focus on the control of this muscle though, as it is the most extensively studied upper airway dilator muscle in both humans and animals. Moreover, the GG is likely representative of other phasic upper airway dilator muscles and therefore understanding its regulation may have broad implications.

\subsection{The palatal muscles}

The palatal muscles control the stiffness (tensor palatini) and position of the palate (levator veli palatini), tongue (palatoglossus), pharynx (palatopharyngeus) plus the shape of the uvula (musculus uvulae). Given that airway closure in OSA is often in the velopharyngeal airway, these muscles are likely important in the maintenance of upper airway patency. This concept is supported by the observation that electrical stimulation of one of these muscles (the tensor palatini) reduces airway collapsibility in cats (McWhorter et al., 1999). Unfortunately however, these muscles are relatively more difficult to study than the larger GG and thus have received less attention. The muscles are innervated by the pharyngeal branch of the vagus nerve except for the tensor veli palatini which is innervated by the trigeminal nerve. The palatoglossus and levator palatini have also been reported to have respiratory related activity, suggesting that at least these two muscles also receive input from the respiratory neurons or negative pressure reflex circuits.

\subsection{The pharyngeal constrictor muscles}

There are 3 separate pharyngeal constrictor muscles (inferior, middle and superior) that are primarily activated during swallowing to promote pharyngeal closure. However, these muscles may also play a role in stiffening the posterior pharyngeal wall although this may come at a cost of reduced airway calibre. These muscles are innervated by the vagus (pharyngeal plexus) and most studies indicate that the constrictors have minimal respiratory related activity or are active during expiration in humans during quiet wakefulness (Kuna, 2000). There is little evidence that these muscles play a role in apnea pathogenesis and thus will not be discussed further in this review.

\subsection{The hyoid muscles}

These muscles influence hyoid bone position, and are also important in the oropharyngeal stage of swallowing. The hyoid muscles act to either pull the hyoid bone forward and upward (geniohyoid and mylohyoid) or caudally (sternohyoid and thyrohyoid). Simultaneous activation of both muscle types results in ventral/caudal movement of the hyoid bone and it is in this manner that activation of these muscles is thought to result in airway dilation (Van de Graaff et al., 1984). The hyoid muscles are innervated by the hypoglossal (geniohyoid and thyrohyoid), trigeminal (mylohyoid), facial (stylohyoid) and ansa cervialis (sternohyoid) and 
thus the precise motor control differs for each muscle. The activity of the geniohyoid, mylohyoid and sternohyoid are reported to change with respiration (reviewed in Horner, 1996; Kubin and Davies, 2002).

\section{PHARYNGEAL MUSCLE ACTIVITY DURING WAKE/SLEEP}

Much of the work investigating pharyngeal muscle control has focused on the genioglossus muscle. This is likely because of the difficulties in recording other airway dilator muscles and also because the genioglossus has been thought to be particularly important with regard to OSA pathogenesis. This is a result of its elevated activity in OSA, respiratory related activity and response to relevant respiratory stimuli such as $\mathrm{CO}_{2}$ and negative airway pressure. We will review the research regarding this muscle here and make the assumption that other upper airway dilator muscles that have respiratory related activity (such as the palatoglossus and levator palatini) behave in a similar fashion. However, given the known differences in neural control and innervation of the various upper airway dilator muscles, it is certainly possible that this is not the case. We believe that the motor control of muscles that do not demonstrate respiratory related activity (tonic muscles) likely differs dramatically and therefore these muscles will be considered separately, with the tensor palatini used as an example of one such muscle.

\subsection{Pharyngeal muscle control during wakefulness in healthy subjects}

As stated above, genioglossal muscle activity increases during inspiration and remains active during expiration but at a lower level. The respiratory related alteration in genioglossal activity likely arises from two sources. First, the respiratory rhythm generating neurons themselves appear to influence hypoglossal activity and therefore muscle activity increases in proportion to respiratory drive. Second, negative airway pressure is detected primarily in the larynx and elicits a brisk reflex activation of the genioglossus muscle. This can be demonstrated by applying brief sudden pulses of negative pressure to the upper airway. Respiratory drive and reflex activation of the genioglossus likely explain the observation that genioglossal activity is increased with nasal compared to oral breathing, supine versus sitting body position and during inspiratory resistive loading (Basner et al., 1989; Tangel et al., 1992; Douglas et al., 1993; Pillar et al., 2001).

The genioglossus activity present in wakefulness is also in part determined by the $\mathrm{P}_{\mathrm{CO}_{2}}$ and $\mathrm{P}_{\mathrm{O}_{2}}$ levels present. Increases in genioglossus activity in response to chemical stimulation likely occurs via both increases in respiratory drive and increased negative pressure reflex stimulation of the muscle. Genioglossus activity is therefore also dependent on central and peripheral chemoreceptor responsiveness. Finally, there is a long held view that respiratory and upper airway dilator muscles are independently stimulated during wakefulness by what is referred to as a "wakefulness stimulus" that is lost at sleep onset (Phillipson, 1977; Orem, 1990; Lo et al., 2007). Therefore, in summary, genioglossal muscle activity during wakefulness is determined by: 1) central respiratory pattern generator output which includes the $\mathrm{P}_{\mathrm{CO}_{2}}$ and $\mathrm{P}_{\mathrm{O}_{2}}$ levels present and peripheral and central chemoresponsiveness, 2) the magnitude of negative pressure in the airway and the reflex responsiveness to thisnegative pressure and 3) the magnitude of the wakefulness drive to the muscle.

The tonic upper airway dilator muscles such as the tensor palatini generally do not show respiratory modulation in humans, suggesting that the input from respiratory neurons and negative pressure reflex loops are minimal. Consistent with this, the tensor palatini has unchanged activity in response to $\mathrm{CO}_{2}$ or inspiratory resistive loading (Tangel et al., 1992; Malhotra et al., 2000; Pillar et al., 2000), although it has been reported to respond to rapid pulses of negative pressure (Malhotra et al., 2004). Thus the major input to the tonic muscles appears to be the wakefulness stimulus (Lo et al., 2007). 


\subsection{Changes in pharyngeal muscle control in NREM sleep in healthy subjects}

At sleep onset the activity of both respiratory modulated and tonic upper airway dilator muscles falls (Mezzanotte et al., 1996) as does respiratory pump muscle activity (Worsnop et al., 1998). However, shortly after sleep onset (a few breaths to a few minutes) genioglossus muscle activity begins to rise again while the tensor palatini muscle continues to have very low activity as long as the sleep state is maintained (Worsnop et al., 1998). These observations are likely explained as follows: at sleep onset, muscle responsiveness to $\mathrm{P}_{\mathrm{CO}_{2}}, \mathrm{P}_{\mathrm{O}_{2}}$ and negative pressure are reduced. This, in combination with the rapid and immediate loss of the wakefulness stimulus, causes a reduction in upper airway dilator and respiratory pump muscle activity. In a normal healthy individual this often results in a slight increase in upper airway resistance (based on their underlying anatomy and the magnitude of the reduction in muscle activity), and consequently more negative pharyngeal pressures. In addition, $\mathrm{CO}_{2}$ gradually rises due to both the reduction in respiratory pump muscle activity and increased airway resistance. These events stimulate a compensatory increase in respiratory pump muscle activity and increments in the activity of upper airway dilator muscles with respiratory related activity (such as the genioglossus). In contrast, the upper airway dilator muscles that do not respond to negative pressure and $\mathrm{CO}_{2}$ (tonic muscles) continue to loose activity. While the increase in activity of muscles such as the genioglossus likely improves airway patency back toward the waking levels, the persistent decrease in activity of tonic muscles may explain why airway resistance generally remains elevated above waking levels.

\subsection{Changes in muscle activity in OSA patients}

The activity of several upper airway dilator muscles (the genioglossus, tensor palatini, and other palatal muscles) are elevated during relaxed wakefulness in patients with OSA compared to healthy controls (Suratt et al., 1988; Mezzanotte et al., 1992). The application of continuous positive airway pressure (CPAP) during wakefulness reduces the activity of these muscles in both groups. However differences in muscle activity between OSA patients and controls persist (Mezzanotte et al., 1996; Fogel et al., 2005). The neural mechanisms resulting in these changes are not well understood. The fact that nasal CPAP reduces the difference in muscle activity between OSA patients and controls suggests that the higher activity in OSA patients is at least in part a result of reflex activation in response to the greater negative airway pressure (due to compromised pharyngeal anatomy) observed in the OSA patient. The remaining differences in muscle activity between patients and controls on CPAP is unexplained, but could result from increased respiratory drive or alternatively represent some form of neural plasticity (for example, long term facilitation from chronic intermittent hypoxia, see Mitchell et al., 2001 for review). Of note, two recent studies have reported that genioglossus muscle activity is not different between patients with OSA and healthy controls during stable NREM sleep on fully therapeutic CPAP (Jordan et al., 2007; Patil et al., 2007). This observation suggests that the mechanism driving the increased dilator muscle activity during wakefulness in OSA is lost with the combination of CPAP and stable sleep. Thus, it appears that the increased pharyngeal dilator muscle activity in patients with OSA is only in part due to activation of the negative pressure reflex with part of the neuromuscular compensation likely resulting from some form of neural plasticity which is sensitive to sleep.

At sleep onset the upper airway dilator muscle activity is reduced in patients with OSA as it is in controls (Fogel et al., 2005). However, due to the anatomical deficits present, this reduction in activity leads to a marked increase in airway resistance or complete obstruction of the upper airway. Negative airway pressure and $\mathrm{CO}_{2}$ therefore rise very quickly and the genioglossus muscle responds to these stimuli. However, much of the time this increased genioglossal activity does not result in sufficient opening of the airway for adequate ventilation to occur (perhaps because of persistent reductions in the activity of tonic airway muscles or loss of lung volume). In this case $\mathrm{CO}_{2}$, negative pressure and respiratory drive continue to build until an 
arousal from sleep occurs. At this time the activity of all of the airway dilator muscles increase and the airway re-opens. Ventilation then increases, resulting in reversal of the blood gas disturbances and a subsequent reduction in central drive as sleep is re-initiated and the cycle begins again.

\section{NEURAL REGULATION OF SLEEP}

The cortical activation that characterizes wakefulness is generated by a number of neurons including the cholinergic pedunculopontine (PPT) and laterodorsal tegmental (LDT) nuclei, the noradrenergic locus cereuleus (LC), the dopaminergic ventral periaqueductal gray (vPAG), the serotonergic raphe nuclei, and the histaminergic tuberomamillary nucleus (TMN) (Fuller et al., 2006). These neurons have a higher firing frequency during wakefulness than NREM sleep as do neurons in the lateral hypothalamus (LH) which contain orexin (also called hypocretin) which have more recently been demonstrated to have a role in state regulation. These orexin containing neurons appear fundamentally important with regard to the stability of the waking state as orexin knockout mice switch between the wake and sleep states frequently. The orexin containing neurons increase the firing of the other wake active neurons including the TMN, LC and raphe and are therefore thought to drive the state of wakefulness (Figure 2, neurones regulating sleep, see review by Fuller et al., 2006). Most or all of these wake active neurons also inhibit the ventro-lateral preoptic neurons (VLPO) which importantly modulate sleep. During NREM sleep, this situation changes substantially. First, as NREM sleep begins, the VLPO neurons become active which results in direct inhibition of the wake promoting neurons. Thus by reducing the firing of wake promoting neurons, the VLPO increases its own firing. This is referred to as a flipflop switch (Fuller et al., 2006), in which one state or the other is favoured and transitions between states are minimised. Orexin and the circadian pacemaker neurons in the suprachiasmatic nucleus (SCN) act by pushing the switch from one side to the other. While the orexin containing LH neurons influence the sleep switch via direct projections, the SCN has few direct projections to the sleep controlling neurons and appears to influence VLPO via neurones in the ventral subparaventricular zone (vSPZ) and dorsomedial hypothalamic nucleus (DMH). There also appears to be a signal of homeostatic sleep need such that as wakefulness is prolonged, an additional input to the sleep side of the switch increases. As yet, little is known about this pathway. However, adenosine has been implicated as the neuromodulator involved. Thus in summary, the sleep active (VLPO) and wake active (TMN, raphe, LC, orexin) neurons inhibit one another such that once a state is achieved, it is maintained. During wakefulness, orexinergic activity is high and this activates the wake active neurons causing thalamo-cortical activation. As circadian and homeostatic sleep drive increases, there is greater activation of the sleep active neurons (VLPO) such that eventually the system switches to the alternate state (Figure 2, neurones regulating sleep).

Many regions of the sleep regulating regions of the brain (outlined above and reviewed in detail in Fuller et al., 2006) are known to directly project to the hypoglossal motor nucleus and may provide the wakefulness drive to the airway dilator muscles. These regions include the raphe, LC, LH orexin containing neurons, pedunculopontine tegmental (PPT) and laterodorsal tegmental (LDT) nucleus. Several initial studies suggested that the wakefulness stimulus was likely at least in part driven by serotonergic stimulation of the hypoglossal motor nucleus as serotonergic neural activity varies with wake/sleep state and administration of serotonin to the hypoglossal motor nucleus increases genioglossus activity (Horner, 2001). However, more recent studies in freely behaving rats with the vagus nerve intact have shown that inhibition of endogenous serotonin at the hypoglossal motor nucleus does not alter genioglossus muscle activity in wakefulness or sleep (Sood et al., 2006). Using the same freely behaving model, these authors have demonstrated that noradrenergic activation of the hypoglossal motor nucleus (perhaps from the LC or sub-coeruleus) does appear to provide at least part of the endogenous wakefulness drive to the genioglossus. They observed lower genioglossal activity with 
inhibition of alpha1 receptors in naturally occurring wakefulness and NREM sleep but not during REM sleep when muscle activity was already very low (Chan et al., 2006). Thus, while these results suggest that noradrenaline provides some of the wakefulness stimulus, it is likely not the only neuromodulator involved.

\section{NEURAL REGULATION OF BREATHING}

Current evidence suggests that there are two groups of respiratory rhythm generating neurons, the Pre-Boetzinger complex (PBC) and retrotrapezoid nucleus (RTN) or parafacial respiratory group (pFRG), which are proposed to be synchronised under normal conditions to provide the respiratory rhythm (Figure 2, pink box: neurons regulating breathing, reviewed in Feldman and Del Negro, 2006). In vitro slices show that PBC neurons have a respiratory related rhythm that persists when synaptic transmission is blocked, suggesting these cells have intrinsic pacemaker activity. Lesion of the PBC or genetic manipulation which reduce the number of PBC neurons cause markedly abnormal breathing patterns (Feldman and Del Negro, 2006), indicating that the PBC is very important for respiratory rhythm generation. However, there are neurons present in the RTN/pFRG which have pre-inspiratory (pre-I) activity and have been recognised in en bloc preparations (which include the brainstem and spinal chord) to also have pacemaker properties. These neurons can be removed by transection and respiratory rhythm generation remains if the PBC neurons are intact, suggesting the pre-I neurons are not essential for rhythm generation in vivo. However, lesions of these neurons does reduce respiratory frequency and in the neonate they appear to influence respiratory rhythm generation as well, as outlined in a recent review (Feldman and Del Negro, 2006). How this respiratory pattern is output to the hypoglossal motor nucleus is not clear although there does not appear to be a direct connection from the PBC to the hypoglossal motor nucleus (Fay and Norgren, 1997).

Currently the brain regions involved in sensing and signalling $\mathrm{CO}_{2}$ are currently not well understood as many regions of the brain respond to changing $\mathrm{pH}$. However, there is mounting evidence that the RTN (which contain the pre-I neurons) is fundamentally involved in chemoreception perhaps acting as a relay centre for integration of information on $\mathrm{CO}_{2}$ status from other brain regions (Kang et al., 2007). Thus, it may be through the RTN that $\mathrm{CO}_{2}$ stimulates both respiratory pump muscles and hypoglossal motor output. However, whether the neurons driving state (sleep) interact with the RTN and/or PBC directly or at the level of sensing changes in $\mathrm{pH}$ is unknown. Thus, to date we have very little information on how sleep interacts with the neurons controlling breathing and further research into this area is required.

The possible neural pathways for the negative pressure reflex have been delineated in a recent report. These studies in rats outlined a likely pathway for this reflex through the NTS and an area termed the periobex (adjacent to the hypoglossal nucleus and rostral to the obex) (Figure 2, negative pressure reflex circuit, Chamberlin et al., 2007). How sleep interacts with this pathway is unknown. However, the LC and raphe project to both the NTS and the hypoglossal motor nucleus. Thus decrements in the firing of these neurons during sleep could influence reflex activation at either location with at least one study suggesting a role for serotonin in this process (Douse and White, 1996).

Thus, as a result of the studies described above, we have some understanding of how sleep onset with a loss of the "wakefulness stimulus" could lead to a decrement in pharyngeal dilator muscle activation. However, the neural mechanisms by which a change of state influences respiratory drive and negative pressure modulation of upper airway muscle activity have been minimally investigated and are likely important in the pathogenesis of sleep apnea. 


\section{SUMMARY}

OSA is a disorder in which the afflicted individual is reliant on increased upper airway dilator muscle activity to maintain patency of an anatomically compromised upper airway. During sleep this mechanism fails, likely due to loss of the wakefulness drive and decrements in respiratory neural drive and negative pressure responsiveness. However, our understanding of these mechanisms is far from complete. Thus considerable additional work addressing pharyngeal anatomy, physiology and neural control is needed.

\section{Acknowledgments}

We would like to thank Nancy Chamberlin and Atul Malhotra for their helpful comments regarding this manuscript and acknowledge the support of the American Heart Association and National Institutes of Health.

\section{References}

Arzt M, Young T, Finn L, Skatrud JB, Bradley TD. Association of sleep-disordered breathing and the occurrence of stroke. Am J Respir Crit Care Med 2005;172:1447-1451. [PubMed: 16141444]

Basner RC, Simon PM, Schwartzstein RM, Weinberger SE, Weiss JW. Breathing route influences upper airway muscle activity in awake normal adults. J Appl Physiol 1989;66:1766-1771. [PubMed: 2732169]

Brooks D, Horner RL, Kozar LF, Render-Teixeira CL, Phillipson EA. Obstructive sleep apnea as a cause of systemic hypertension. Evidence from a canine model. J Clin Invest 1997;99:106-109. [PubMed: 9011563]

Chamberlin NL, Eikermann M, Fassbender P, White DP, Malhotra A. Genioglossus premotoneurons and the negative pressure reflex in rats. J Physiol 2007;579:515-526. [PubMed: 17185342]

Chan E, Steenland HW, Liu H, Horner RL. Endogenous excitatory drive modulating respiratory muscle activity across sleep-wake states. Am J Respir Crit Care Med 2006;174:1264-1273. [PubMed: 16931636]

Doherty LS, Kiely JL, Swan V, McNicholas WT. Long-term Effects of Nasal Continuous Positive Airway Pressure Therapy on Cardiovascular Outcomes in Sleep Apnea Syndrome. Chest 2005;127:20762084. [PubMed: 15947323]

Douglas NJ, Jan MA, Yildirim N, Warren PM, Drummond GB. Effect of posture and breathing route on genioglossal electromyogram activity in normal subjects and in patients with the sleep apnea/hypopnea syndrome. Am Rev Resp Dis 1993;148:1341-1345. [PubMed: 8239173]

Douse MA, White DP. Serotonergic effects on hypoglossal neural activity and reflex responses. Brain Res 1996;726:213-222. [PubMed: 8836563]

Fay RA, Norgren R. Identification of rat brainstem multisynaptic connections to the oral motor nuclei using pseudorabies virus. III. Lingual muscle motor systems. Brain Res Brain Res Rev 1997;25:291311. [PubMed: 9495560]

Feldman JL, Del Negro CA. Looking for inspiration: new perspectives on respiratory rhythm. Nat Rev Neurosci 2006;7:232-242. [PubMed: 16495944]

Fogel RB, Trinder J, White DP, Malhotra A, Raneri J, Schory K, Kleverlaan D, Pierce RJ. The effect of sleep onset on upper airway muscle activity in patients with sleep apnoea versus controls. J Physiol 2005;564:549-562. [PubMed: 15695240]

Fuller PM, Gooley JJ, Saper CB. Neurobiology of the sleep-wake cycle: sleep architecture, circadian regulation, and regulatory feedback. J Biol Rhythms 2006;21:482-493. [PubMed: 17107938]

Horner RL. Motor control of the pharyngeal musculature and implications for the pathogenesis of obstructive sleep apnea. Sleep 1996;19:827-853. [PubMed: 9085493]

Horner RL. The neuropharmacology of upper airway motor control in the awake and asleep states: implications for obstructive sleep apnoea. Respir Res 2001;2:286-294. [PubMed: 11686898]

Jordan AS, Schory K, Dover L, Fogel RB, Malhotra A, White DP. Genioglossus muscle activity during stable sleep in patients with obstructive sleep apnea [Abstract]. Am J Resp Crit Care Med 2005;2:A610. 
Jordan AS, Wellman A, Heinzer RC, Lo YL, Schory K, Dover L, Gautam S, Malhotra A, White DP. Mechanisms Used To Restore Ventilation After Partial Upper Airway Collapse During Sleep In Humans. Thorax. 2007In Press

Jordan AS, White DP, Fogel RB. Recent advances in understanding the pathogenesis of obstructive sleep apnea. Curr Opin Pulm Med 2003;9:459-464. [PubMed: 14534395]

Kang BJ, Chang DA, Mackay DD, West GH, Moreira TS, Takakura AC, Gwilt JM, Guyenet PG, Stornetta RL. Central nervous system distribution of the transcription factor Phox $2 b$ in the adult rat. J Comp Neurol 2007;503:627-641. [PubMed: 17559094]

Kay A, Trinder J, Bowes G, Kim Y. Changes in airway resistance during sleep onset. J Appl Physiol 1994;76:1600-1607. [PubMed: 8045838]

Kim HC, Young T, Matthews CG, Weber SM, Woodward AR, Palta M. Sleep-disordered breathing and neuropsychological deficits. A population-based study. Am J Respir Crit Care Med 1997;156:18131819. [PubMed: 9412560]

Kobayashi I, Perry A, Rhymer J, Wuyam B, Hughes P, Murphy K, Innes JA, McIvor J, Cheesman AD, Guz A. Inspiratory coactivation of the genioglossus enlarges retroglossal space in laryngectomized humans. J Appl Physiol 1996;80:1595-1604. [PubMed: 8727545]

Kryger, MH.; Roth, T.; Dement, WC. Principles and Practice of Sleep Medicine. Elsevier Saunders; 2005.

Kubin, L.; Davies, RO. Mechanisms of Airway Hypotonia. In: Pack, AI., editor. Pack AIs Sleep Apnea: Pathogenesis, Diagnosis and Treatment. New York: Marcel Dekker; 2002. p. 99-154.

Kuna ST. Respiratory-related activation and mechanical effects of the pharyngeal constrictor muscles. Respir Physiol 2000;119:155-161. [PubMed: 10722858]

Lo YL, Jordan AS, Malhotra A, Wellman A, Heinzer RA, Eikerman M, Schory K, Dover L, White DP. The Influence of Wakefulness on Pharyngeal Airway Muscle Activity. Thorax. 2007In Press

Malhotra A, Pillar G, Fogel RB, Beauregard J, Edwards JK, Slamowitz DI, Shea SA, White DP. Genioglossal but not palatal muscle activity relates closely to pharyngeal pressure. Am J Respir Crit Care Med 2000;162:1058-1062. [PubMed: 10988130]

Malhotra A, Trinder J, Fogel R, Stanchina M, Patel SR, Schory K, Kleverlaan D, White DP. Postural effects on pharyngeal protective reflex mechanisms. Sleep 2004;27:1105-1112. [PubMed: 15532204]

Marin JM, Carrizo SJ, Vicente E, Agusti AG. Long-term cardiovascular outcomes in men with obstructive sleep apnoea-hypopnoea with or without treatment with continuous positive airway pressure: an observational study. Lancet 2005;365:1046-1053. [PubMed: 15781100]

McWhorter AJ, Rowley JA, Eisele DW, Smith PL, Schwartz AR. The effect of tensor veli palatini stimulation on upper airway patency. Arch Otolaryngol Head Neck Surg 1999;125:937-940. [PubMed: 10488975]

Mezzanotte WS, Tangel DJ, White DP. Waking genioglossal electromyogram in sleep apnea patients versus normal controls (a neuromuscular compensatory mechanism). J Clin Invest 1992;89:15711579. [PubMed: 1569196]

Mezzanotte WS, Tangel DJ, White DP. Influence of sleep onset on upper-airway muscle activity in apnea patients versus normal controls. Am J Respir Crit Care Med 1996;153:1880-1887. [PubMed: 8665050]

Mitchell GS, Baker TL, Nanda SA, Fuller DD, Zabka AG, Hodgeman BA, Bavis RW, Mack KJ, Olson EB Jr. Invited review: Intermittent hypoxia and respiratory plasticity. J Appl Physiol 2001;90:24662475. [PubMed: 11356815]

Orem J. The nature of the wakefulness stimulus for breathing. Prog Clin Biol Res 1990;345:23-30. [PubMed: 2198591]

Patil SP, Schneider H, Marx JJ, Gladmon E, Schwartz AR, Smith PL. Neuromechanical control of upper airway patency during sleep. J Appl Physiol 2007;102:547-556. [PubMed: 17008440]

Peppard PE, Young T, Palta M, Skatrud J. Prospective study of the association between sleep-disordered breathing and hypertension. N Engl J Med 2000;342:1378-1384. [PubMed: 10805822]

Pepperell JC, Ramdassingh-Dow S, Crosthwaite N, Mullins R, Jenkinson C, Stradling JR, Davies RJ. Ambulatory blood pressure after therapeutic and subtherapeutic nasal continuous positive airway pressure for obstructive sleep apnoea: a randomised parallel trial. Lancet 2002;359:204-210. [PubMed: 11812555] 
Phillipson EA. Regulation of breathing during sleep. Am Rev Respir Dis 1977;115:217-224. [PubMed: 194508]

Pillar G, Fogel RB, Malhotra A, Beauregard J, Edwards JK, Shea SA, White DP. Genioglossal inspiratory activation: central respiratory vs mechanoreceptive influences. Respir Physiol 2001;127:23-38. [PubMed: 11445198]

Pillar G, Malhotra A, Fogel R, Beauregard J, Schnall R, White DP. Airway mechanics and ventilation in response to resistive loading during sleep: influence of gender. Am J Respir Crit Care Med 2000;162:1627-1632. [PubMed: 11069787]

Punjabi NM, O'Hearn DJ, Neubauer DN, Nieto FJ, Schwartz AR, Smith PL, Bandeen-Roche K. Modeling hypersomnolence in sleep-disordered breathing. A novel approach using survival analysis. Am J Respir Crit Care Med 1999;159:1703-1709. [PubMed: 10351907]

Schwab RJ. Pro: sleep apnea is an anatomic disorder. Am J Respir Crit Care Med 2003;168:270-271. [PubMed: 12888606]

Schwab RJ, Gupta KB, Gefter WB, Metzger LJ, Hoffman EA, Pack AI. Upper airway and soft tissue anatomy in normal subjects and patients with sleep-disordered breathing. Significance of the lateral pharyngeal walls. Am J Respir Crit Care Med 1995;152:1673-1689. [PubMed: 7582313]

Series F. Upper airway muscles awake and asleep. Sleep Med Rev 2002;6:229-242. [PubMed: 12531123]

Sood S, Raddatz E, Liu X, Liu H, Horner RL. Inhibition of serotonergic medullary raphe obscurus neurons suppresses genioglossus and diaphragm activities in anesthetized but not conscious rats. J Appl Physiol 2006;100:1807-1821. [PubMed: 16484356]

Strohl KP. Con: sleep apnea is not an anatomic disorder. Am J Respir Crit Care Med 2003;168:271-272. [PubMed: 12888607]

Suratt PM, McTier RF, Wilholt SC. Upper airway muscle activation is augmented in patients with obstructive sleep apnea compared to that in normal subjects. Am Rev Respir Dis 1988;137:889-894. [PubMed: 3354997]

Tangel DJ, Mezzanotte WS, Sandberg EJ, White DP. Influences of NREM sleep on the activity of tonic vs. inspiratory phasic muscles in normal men. J Appl Physiol 1992;73:1058-1066. [PubMed: 1400018]

Trinder J, Kay A, Kleiman J, Dunai J. Gender differences in airway resistance during sleep. J Appl Physiol 1997;83:1986-1997. [PubMed: 9390972]

Van de Graaff WB, Gottfried SB, Mitra J, van Lunteren E, Cherniack NS, Strohl KP. Respiratory function of hyoid muscles and hyoid arch. J Appl Physiol 1984;57:197-204. [PubMed: 6469781]

White, DP. Respiration and the human upper airway. In: Altose, MD.; Kawakami, Y.; Altose, MD.; Kawakami, Ys, editors. Control of breathing in health and disease. New York: Marcel Dekker; 1999. p. 163-201.

Worsnop C, Kay A, Pierce R, Kim Y, Trinder J. Activity of respiratory pump and upper airway muscles during sleep onset. J Appl Physiol 1998;85:908-920. [PubMed: 9729564]

Yaggi HK, Concato J, Kernan WN, Lichtman JH, Brass LM, Mohsenin V. Obstructive sleep apnea as a risk factor for stroke and death. N Engl J Med 2005;353:2034-2041. [PubMed: 16282178]

Younes M. Contributions of upper airway mechanics and control mechanisms to severity of obstructive apnea. Am J Respir Crit Care Med 2003;168:645-658. [PubMed: 12773321]

Young T, Blustein J, Finn L, Palta M. Sleep-disordered breathing and motor vehicle accidents in a population- based sample of employed adults. Sleep 1997;20:608-613. [PubMed: 9351127]

Young T, Palta M, Dempsey J, Skatrud J, Weber S, Badr S. The occurrence of sleep-disordered breathing among middle-aged adults. New Engl J Med 1993;328:1230-1235. [PubMed: 8464434] 

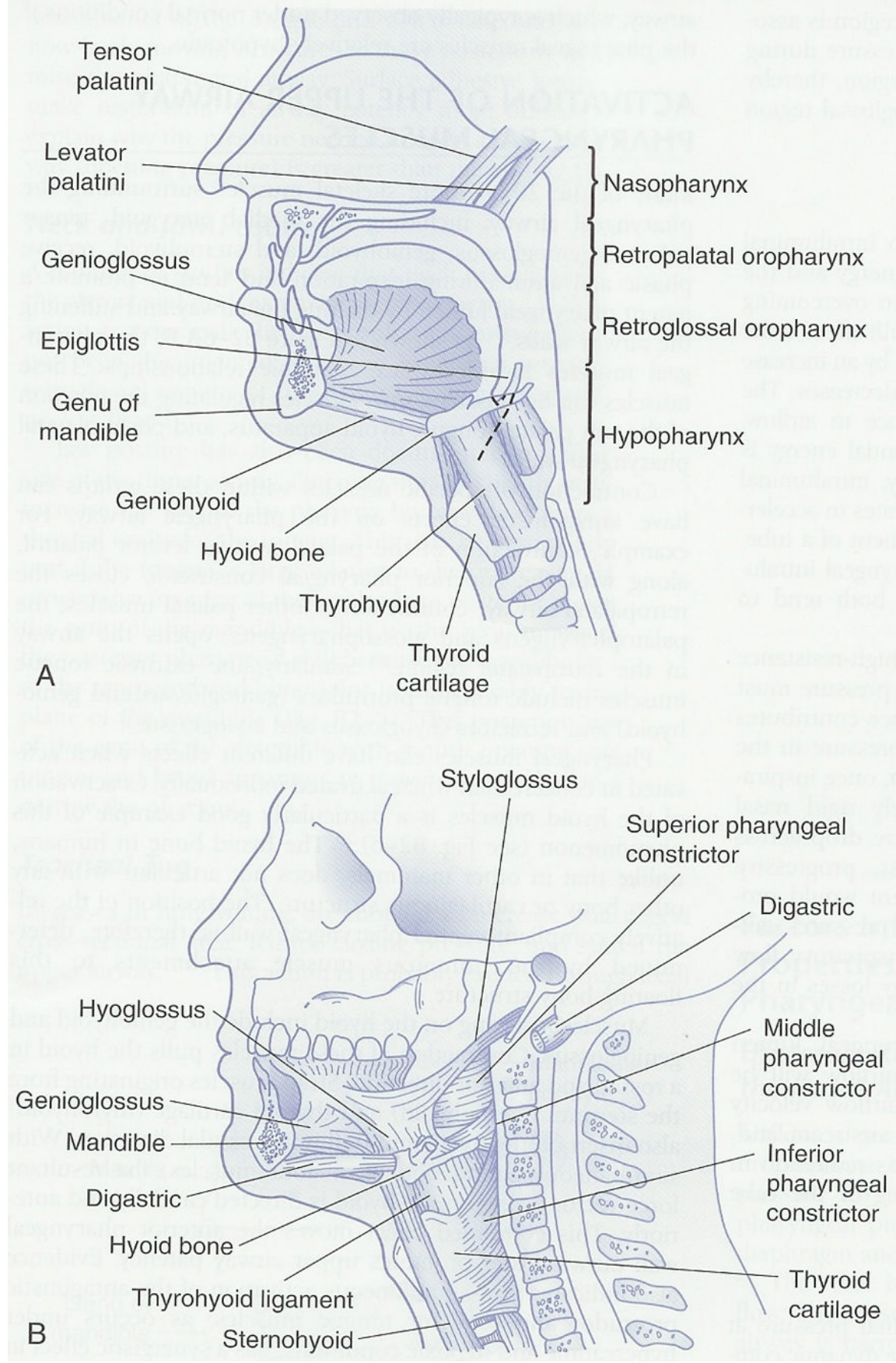

Figure 1. The pharyngeal airway anatomy and upper airway dilator muscles

Midsagittal (A) and parasagittal (B) representations of the pharyngeal airway anatomy showing tongue, soft palate, hyoid bone and pharyngeal constrictor muscle location. Reprinted with permission from Principles and Practice of Sleep Medicine. Kryger, Roth and Dement, Page 988, Copyright Elsevier 2005 (Kryger et al., 2005). 


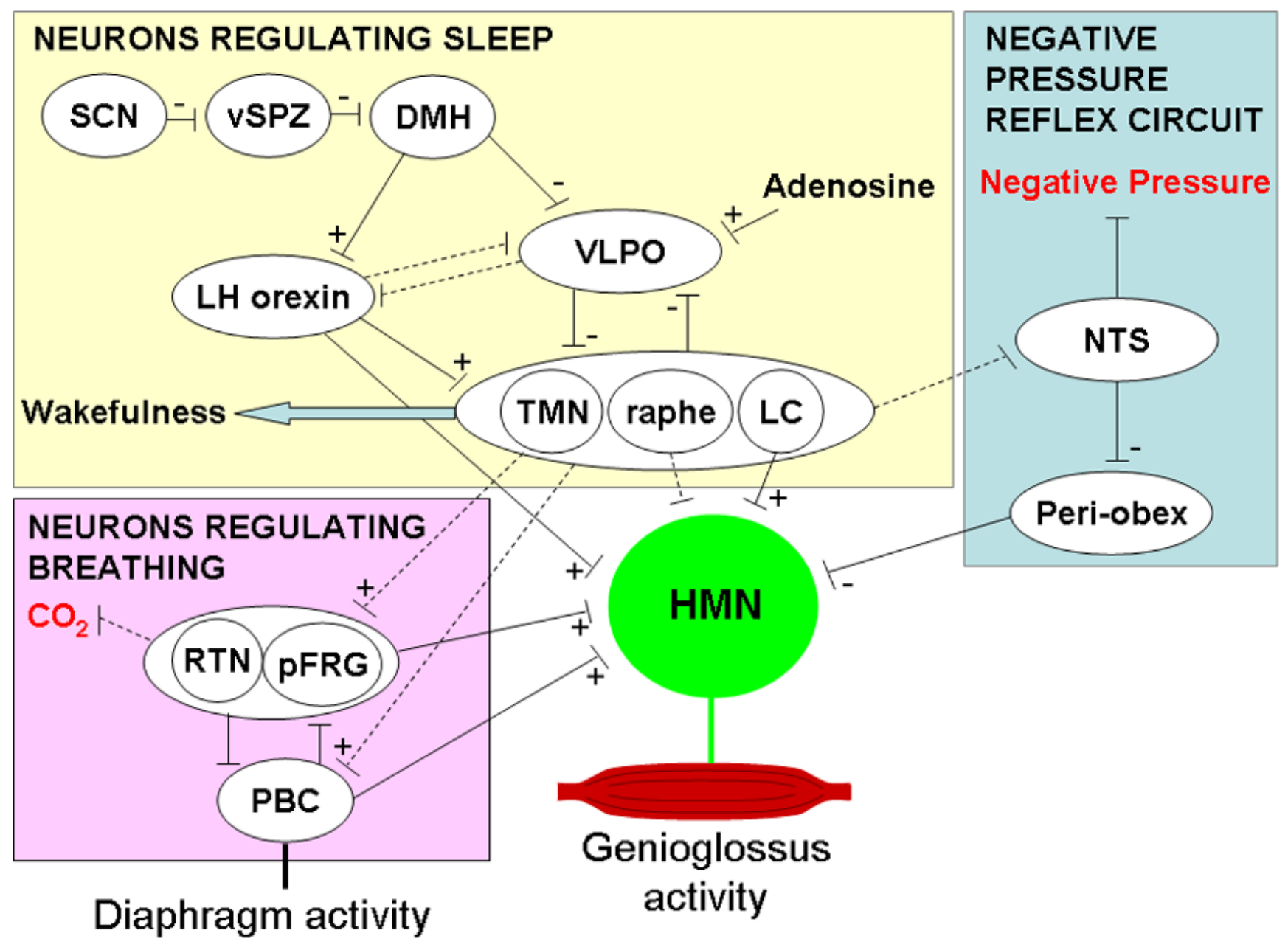

Figure 2. Proposed control of hypoglossal motor output to the genioglossus muscle The hypoglossal motor nucleus (HMN) receives input from neurons involved in negative pressure reflex circuits, and those controlling sleep and breathing. See text for detailed explanation of the pathways involved or the following articles (Feldman and Del Negro, 2006; Fuller et al., 2006; Chamberlin et al., 2007). Dotted lines represent proposed pathways with the exception of the raphe where connections to the HMN are well documented but not believed to contribute to the state related changes in HMN activity. SCN suprachiasmatic nucleus, vSPZ ventral subparaventricular zone, DMN dorsomedial hypothalamic nucleus, VLPO ventrolateral preoptic nucleus, LH orexin Lateral hypothalamic orexinergic neurons, LC locus coeruleus, TMN tuberomamillary nucleus, pFRG parafacial respiratory group, RTN retrotrapezoid nucleus, PBC pre-boetzinger complex, NTS nucleus of the solitary tract. Some arrows have been omitted for clarity. 